\title{
Softwares Educativos para Alunos com Deficiência Intelectual: Estratégias UTILIZADAS ${ }^{1}$ \\ EDUCATIONAL SOFTWARE FOR STUDENTS With INTELLECTUAL Disabilities: SELECTED STRATEGIES
}

\author{
Ketilin Mayra PEDRO \\ Miguel Claudio Moriel CHACON ${ }^{3}$
}

\begin{abstract}
RESUMO: o computador está presente no cotidiano escolar e sua utilizaçáo, por meio de softwares educativos, deve ser mediado e planejado para que esse recurso contribua para a aprendizagem dos alunos, inclusive aqueles com deficiência intelectual (DI). Sendo assim, tivemos por objetivo propor atividades específicas de informática para alunos com DI, por meio de softwares educativos, além de quantificar e analisar as estratégias técnicas e pedagógicas utilizadas. Participaram da pesquisa seis alunos categorizados como DI, matriculados em duas escolas públicas. Para coletar informaçóes utilizamos protocolos de observação e diário de campo. Os dados foram analisados de maneira quantitativa e qualitativa, sendo estes baseados nos conceitos de mediação e zona de desenvolvimento proximal da teoria histórico-cultural. Os resultados indicaram que se os conteúdos trabalhados nas aulas de informática convergirem com as atividades propostas em sala de aula, os alunos com DI têm oportunidades de experienciar atividades diferenciadas que lhes possibilitem o sucesso. Observamos que foram as estratégias de ensino que possibilitaram aos alunos participantes compreender e realizar corretamente as atividades propostas. Dessa maneira, consideramos que os conhecimentos técnicos a respeito dos softwares educativos e os conhecimentos pedagógicos sobre o conteúdo que está sendo trabalhado, não são suficientes para que a atividade proposta contribua para o desenvolvimento de alunos com DI.
\end{abstract}

PALAVRAS-CHAVE: Educação Especial. Softwares Educativos. Deficiência Intelectual. Estratégias Técnicas e Pedagógicas.

ABSTRACT: The computer is present in everyday school life and using it with educational software must be mediated and planned in order for this resource to contribute to student learning, including those with intellectual disabilities (ID). Therefore, the aim was to propose specific computer activities for students with ID using educational software, and to quantify and analyze the technical and pedagogical strategies used. The participants were six students with ID enrolled in two public schools. To collect information we used observation protocols and a field journal. Data were analyzed quantitatively and qualitatively, based on the concepts of mediation and the zone of proximal development of cultural-historical theory. The results indicated that when the content developed in the computer classes were compatible with the proposed activities in the classroom, students with ID had opportunities to experience different activities that enable them to be successful. We noted that what enabled them to understand and correctly perform the proposed activities were the teaching strategies. Thus, we consider that technical knowledge about educational software and pedagogical knowledge about content that is being worked on, are insufficient to ensure that the proposed activity will contribute to the development of students with ID.

KEYWORDS: Special Education. Educational Software. Intellectual Disability. Technical and Pedagogical Strategies.

\section{INTRODUÇÃo}

São indispensáveis as adaptaçóes, ao se falar sobre inclusão de alunos com deficiência em sala de aulas comuns. Por vezes, pequenas adaptaçóes nas atividades sáo suficientes para se ter sucesso, durante a execuçáo das atividades propostas em sala, como, por exemplo: engrossador

\footnotetext{
${ }^{1}$ Apoio Financeiro Capes.

${ }^{2}$ Pedagoga. Mestre pela Em Educação e Doutoranda do Programa De Pós-Graduação Em Educação Da FFC - UNESP/Marília. ketilinp@yahoo.com.br

${ }^{3}$ Psicólogo. Mestre, Doutor em Educação e Pós-Doutorado pela Universidade Federal de Santa Maria. Professor Assistente Doutor do Departamento de Educação Especial e do Programa de Pós-Graduação em Educação da FFC - UNESP/Marília. miguelchacon@marilia.unesp.br
} 
de lápis ou caneta, ampliação da fonte para leitura, utilização de letras maiúsculas em textos, materiais didáticos em tamanho ampliado. Em outras situaçóes, é necessário recorrer a recursos mais sofisticados, como o computador, que por meio de softwares ${ }^{4}$ educativos pode ser um excelente recurso pedagógico para a aprendizagem do aluno com deficiência. Atualmente, há diversos softwares e equipamentos adequados/adaptados para trabalhar, especificamente, com esses alunos.

Segundo Delville et al. (1999), o uso das tecnologias no campo das deficiências se realiza em diversos setores de aplicação: auxílio à comunicação, auxílio à vida cotidiana, aprendizado e desenvolvimento cognitivo.

Schmitz (2002) afirma que a informática é um

[...] poderoso meio auxiliar de informação e aprendizagem, precisa ser posta à disposição de professores/as e alunos/as para reforçar sua atuação e aprendizagem. Ela pode fornecer informaçóes preciosas que poderão ampliar e aprofundar os conhecimentos alcançados de outras fontes. (SCHMITZ, 2002, p. 46).

Frente ao rumo que vem tomando a educação na denominada "sociedade da informação" e diante do exposto, é evidente a necessidade de se propor novas alternativas para que alunos com deficiência, incluídos em sala de aula comum, aprendam melhor e desenvolvam ao máximo suas potencialidades. Embora os objetivos sejam os mesmos para todos os alunos, o conteúdo a ser ensinado, as atividades a serem desenvolvidas e as estratégias de ensino precisam de adaptaçóes, respeitando as potencialidades de cada um.

Bezerra (2010) analisou as estratégias usadas por professores de Educação Física que possuíam alunos com deficiência matriculados em suas aulas. Os resultados apontaram o emprego de diferenciadas estratégias de ensino, como de organização dos alunos no espaço da quadra, instrução, convivência, adaptação e ensino inclusivo, além da necessidade de o professor planejar, flexibilizar, criar e oportunizar a criação de estratégias em todos os instantes da aula, para que ocorra a inclusão dos alunos com deficiência.

A escolha mais adequada da estratégia possibilita o sucesso da aprendizagem, pois amplia suas experiências, a criatividade e a flexibilidade. As estratégias permitem a motivação e a participação do aluno, além de atender às diferenças individuais, o que amplia as experiências de aprendizagem dos alunos (MASSETO, 1995).

Os professores precisam saber diferenciar estratégia de recurso pedagógico. Estratégia pode ser definida como “[...] uma ação do professor, que na maioria das vezes utiliza um recurso pedagógico para alcançar um objetivo específico de ensino ou de avaliação" (MANZINI, 2010, p. 126). Para esse autor, a estratégia também deve ser planejada anteriormente, considerandose as características do aluno, o objetivo e o nível de complexidade da atividade, sendo flexível e passível de ser modificada para ter funcionalidade ao aluno. Pontua ainda que modificar a estratégia de ensino possibilita ao professor conhecer as potencialidades e o nível de

${ }^{4}$ Utilizaremos a palavra software em itálico, porque, embora esteja incorporada ao vocabulário da língua portuguesa, é escrita dessa maneira.

${ }^{5}$ Quando utilizarmos a nomenclatura informática, referimo-nos à ciência da informática, de maneira geral, não priorizando nenhum dos seus recursos. 
conhecimento dos alunos, o que pode servir de base para planejar novas atividades e estratégias. Além da possibilidade de uma estratégia ter sucesso ou não, durante o desenvolvimento de uma determinada atividade, existem fatores biológicos e ambientais que podem interferir na estratégia, como, por exemplo, cansaço do aluno, nível de dificuldade da atividade etc.

Diferentemente da estratégia, recurso pedagógico é concebido como um “[...] objeto que apresenta três componentes: ser algo concreto, manipulável e com finalidade pedagógica” (MANZINI, 2010, p.112). Sendo assim, computadores e/ou softwares são recursos pedagógicos e como tais devem compor o planejamento de aula, cujas estratégias devem ser previamente delineadas.

O computador, como recurso pedagógico, é um meio e não um fim em si mesmo, de modo que, embora ele possa colaborar para maior autonomia e desenvolvimento dos alunos, na área educacional, seu uso deve ser mediado pelo professor, perante a necessidade de estabelecer objetivos e conteúdos, escolher softwares e avaliar o processo de aprendizagem.

Ademais, a existência desses recursos (computadores e softwares educativos) pode proporcionar atenção individualizada aos alunos, sendo que a atividade avança na medida em que a resposta dada pelo aluno for correta, sendo elogiado ou informado do erro, caso no qual normalmente terá outra chance para responder (OLIVEIRA, 1997).

Hoje, os computadores podem ser empregados por todos os alunos, inclusive aqueles com deficiência, seja qual for sua modalidade, visto que atualmente existe no mercado uma grande variedade de softwares que atende às especificidades de cada deficiência.

A escolha do software educativo a ser usado requer atenção e planejamento por parte do professor. É necessário que as escolhas convirjam com os objetivos a serem alcançados na aprendizagem, e diferenciem os que objetivam testar conhecimentos dos que procuram levar o aluno a interagir com o programa, de maneira a construir o conhecimento (SILVA, 2006).

Ao propormos a utilização de tecnologias educacionais, como o computador, é preciso escolher planejadamente o conteúdo e o software educativo a ser trabalhado. Para Garcia (2007), é indispensável que o atendimento às especificidades desses alunos esteja vinculado diretamente à referência curricular da série onde estão matriculados, para não correr o risco de elaborar propostas de aprendizagem com base na vertente médico-pedagógica (ideia de correção, ajustamento e adaptação).

Além de um bom planejamento acerca do que será trabalhado por intermédio do computador e de uma escolha cuidadosa do software educativo, é necessário que toda essa prática educativa seja mediada pelo professor.

Adotando a teoria sócio-histórica, abordamos a Zona de Desenvolvimento Proximal (ZDP), que é definida como

[...] a distância entre o nível de desenvolvimento real, que se costuma determinar através da solução independente de problemas, e o nível de desenvolvimento potencial, determinado através da soluçáo de problemas sob a orientação de um adulto ou em colaboração com companheiros mais capazes (VYGOTSKY, 1984, p. 97). 
Para Oliveira (1993), Vygotsky estabelece forte relação entre o processo de desenvolvimento e a relação do indivíduo com seu ambiente sociocultural e com sua situação de organismo que não se desenvolve plenamente sem o suporte de outros indivíduos; e é na ZPD que a interferência de outros indivíduos é mais transformadora. Esse conceito reforça a ideia da aprendizagem mediada, em que a vida social é fundamental na relação entre os sujeitos e os artefatos.

Silva e Lima (2011) sublinham a natureza simbólica das tecnologias e a possibilidade de acesso à informação e interação social e, consequentemente, a experiência sociocultural proporcionada pelo uso, levando o sujeito a operar mentalmente ou a se desenvolver cognitivamente.

Vygotsky (1984) pontua que, na relação entre desenvolvimento e aprendizado, somente o aprendizado adequadamente organizado resulta em desenvolvimento mental e póe em movimento vários processos de desenvolvimento que, de outra forma, seriam impossíveis de acontecer. Seguindo essa perspectiva, o educador assume o papel de mediador, oferecendo suporte ao aluno na sua ZPD. Dessa forma, as Tecnologias da Informação e Comunicação (TIC) são concebidas como um recurso pedagógico que necessita de uma mediação do professor, para que possam ser efetivas no processo de ensino-aprendizagem.

Em consequência, é na ZDP que o aprendizado pode ser definido em termos do desenvolvimento do sujeito e onde o papel do mediador como suporte externo é importante. A educação consiste, portanto, no acompanhamento do desempenho por meio da ZDP, em que há vários meios e níveis pelos quais esse acompanhamento pode ser fornecido; um bom planejamento e gerenciamento do desempenho assistido se revelam na criação de cenários adequados para o desenvolvimento de atividades pedagógicas (LIMA, 2003).

De acordo com Vianna (2006), utilizar as TIC num contexto de mediação é a forma mais apropriada de garantir a aprendizagem significativa dos alunos. Mais do que assumir essa perspectiva, é preciso explicitar a si mesmo as teorias pessoais que se imbricam em tal escolha, para que, dessa maneira, o professor adote estratégias e selecione criticamente as ferramentas computadorizadas, sem banalizar seu uso.

Silva e Lima (2011) destacam que a TIC usada mediante a proposta de ZPD leva o aluno a administrar o conteúdo de ensino que está além de seu desenvolvimento real, estimula o desenvolvimento cognitivo, criando, por meio de atividades e intervençóes, novas zonas de desenvolvimento proximal. Nesse processo, o professor é fundamental para o planejamento das atividades mediadas pelas tecnologias.

É nessa perspectiva que um bom planejamento pedagógico tem relevância na utilização dos recursos tecnológicos, por alunos com deficiência. O mero treinamento para o trabalho com o computador, por mais importante que seja náo resolve o problema. Por isso, é importante mostrar que a função de professor não está ameaçada, uma vez que o apelo ao software educativo como recurso pedagógico só é significativo com sua mediação.

Assim, os softwares educativos constituem um recuso pedagógico à disposição de todos os alunos e, se seu emprego ocorrer de forma planejada e sistematizada, trará grandes 
contribuiçốes ao desenvolvimento da aprendizagem. Nesse sentido, é necessário que se faça uma seleção e um planejamento adequado para o uso de tais recursos.

Diante do que foi exposto, tivemos por objetivo propor atividades específicas de informática para alunos com deficiência intelectual (DI), por meio de softwares educativos, além de quantificar e analisar as estratégias técnicas e pedagógicas que possibilitaram o acesso ao computador e a compreensão da atividade.

\section{Método}

Foi realizado junto à Secretaria Municipal de Educação, de uma cidade de médio porte do interior do Estado de São Paulo, um mapeamento em relaçáo aos alunos com deficiência, matriculados na rede regular de ensino. Primeiramente, foram selecionados alunos de Ensino Fundamental I ( $1^{\circ}$ ao $5^{\circ}$ ano) que apresentavam DI. Após o levantamento desses alunos, visitamos as escolas, a fim de pedir o consentimento para a execução da pesquisa junto a esses alunos. Selecionamos as escolas que, além de se interessarem pelo estudo, estavam localizadas na mesma região da cidade. Obtivemos o aceite das escolas e enviamos o projeto ao Comitê de Ética ${ }^{6}$.

\subsection{CaracterizaÇÁo das escolas}

As duas escolas envolvidas na pesquisa contavam com laboratório de informática e instrutores na área. Apenas na escola A havia dois profissionais, sendo um efetivo na função e o outro estagiário.

A Tabela 1 apresenta o número total de alunos, alunos participantes, professores, instrutores de informática e computadores de cada escola.

Tabela 1 - Caracterização das escolas.

\begin{tabular}{lc|c|c|c|c}
\hline Escolas & $\begin{array}{c}\text { No. Total de } \\
\text { alunos }\end{array}$ & $\begin{array}{c}\text { No. De alunos } \\
\text { participantes }\end{array}$ & $\begin{array}{c}\text { No. Total de } \\
\text { professores }\end{array}$ & $\begin{array}{c}\text { No. Instrutores } \\
\text { de informática }\end{array}$ & No de computadores \\
A & 389 & 2 & 22 & 2 & 20 \\
B & 570 & 4 & 27 & 1 & 24 \\
\hline
\end{tabular}

Fonte: Elaboração Própria

Nas escolas envolvidas, a informática é concebida, conforme apresenta Borges Neto (1999), como "informática na educação", de sorte que os softwares educativos devem ser um dos suportes à aprendizagem dos alunos.

Nessas escolas, as aulas de informática são realizadas sistematicamente. Segundo Miranda (2008), a prática sistematizada acontece quando os horários são definidos previamente para a utilização do aluno, por exemplo, o semanal/quinzenal já estabelecido pelo professor ou coordenação. Salientamos que algumas instituiçóes de ensino realizam uma prática "não

${ }^{6}$ Projeto de pesquisa aprovado por comitê de ética, parecer n. 0837/2010. 
sistematizada" do laboratório de informática, na qual o uso depende do interesse do professor e da necessidade do aluno.

Apesar de não concordarmos de ser essa a maneira mais adequada de proporcionar aos alunos o acesso aos computadores e/ou softwares educativos, era desse modo que a adoção desse recurso estava concebida nas escolas.

As informações constantes dos projetos político-pedagógico das escolas foram relevantes para conhecermos a perspectiva dos profissionais que compóem as escolas, diante do uso dos computadores e seus recursos, no contexto educacional.

\subsection{Participantes da PesQuisa}

Os alunos selecionados encontravam-se matriculados no Ensino Fundamental I, distribuídos em três escolas de um bairro periférico da cidade de Marília e, conforme informaçôes obtidas nas escolas, esses alunos apresentavam condiçóes de manusear o equipamento.

Salientamos que os participantes não recebiam atendimento educacional especializado (AEE) e o único momento de contato com os computadores e seus recursos, dentro do ambiente escolar, era nas aulas de informática, sendo que essa era uma prática sistematizada das escolas nas quais estavam matriculados.

O Quadro 1 mostra a caracterização dos seis alunos participantes, com nomes fictícios. Para identificar a série dos alunos, mantivemos a nomenclatura utilizada pelas escolas na época da pesquisa, que contemplava anos e séries.

Quadro 1 - Caracterização dos alunos participantes.

\begin{tabular}{|l|c|c|c|c|c|}
\hline Identificaçáo & Idade & Escola & Série & Diagnóstico & Outras caracterizaçóes \\
\hline Mário & 7 & $\mathrm{~B}$ & $1^{\circ}$ ano & $\begin{array}{c}\text { Deficiência Inte- } \\
\text { lectual }\end{array}$ & \\
\hline Joáo & 7 & $\mathrm{~A}$ & $1^{\circ}$ ano & $\begin{array}{c}\text { Síndrome de } \\
\text { Down }\end{array}$ & \\
\hline Marcos & 8 & $\mathrm{~B}$ & $3^{\circ}$ ano & $\begin{array}{c}\text { Deficiência Inte- } \\
\text { lectual }\end{array}$ & $\begin{array}{c}\text { Comprometimento de membros } \\
\text { inferiores e superiores }\end{array}$ \\
\hline Fernando & 10 & $\mathrm{~B}$ & $3^{30}$ ano & $\begin{array}{c}\text { Deficiência Inte- } \\
\text { lectual }\end{array}$ & \\
\hline José & 12 & $\mathrm{~A}$ & $4^{\mathrm{a}}$ série & $\begin{array}{c}\text { Deficiência Inte- } \\
\text { lectual }\end{array}$ & Dificuldades de fala. \\
\hline Maria & 13 & $\mathrm{~B}$ & $4^{\mathrm{a}}$ série & $\begin{array}{c}\text { Deficiência Inte- } \\
\text { lectual }\end{array}$ & \\
\hline
\end{tabular}

Fonte: Elaboração Própria 


\subsection{Instrumentos de Avaliaçáo e Registro}

Para o registro das intervenções de informática, foi elaborado um protocolo de observação que contemplava o objetivo e conteúdo das atividades, adaptaçóes feitas e o desempenho do aluno nas atividades propostas.

Segundo Danna e Matos (1999, p. 40), “[...] o protocolo de observação é a folha onde o observador registra os dados coletados. Um protocolo contém uma série de itens, que abrangem as informaçóes relevantes para a análise dos comportamentos". O protocolo desta pesquisa foi elaborado a partir do modelo sugerido pelas autoras. Sobre a observação, as autoras enfatizam que os dados coletados a partir da observação fornecem subsídios para se diagnosticar uma determinada situação, facilitar a escolha das técnicas e procedimentos usados na pesquisa e na avaliação da sua eficácia.

\subsection{Recursos Utilizados}

Para a escolha dos softwares educativos a serem empregados, realizamos uma varredura em sites de busca na internet, priorizando os de compras e de fabricantes, sendo que os softwares selecionados são brasileiros e estáo disponíveis no mercado. Procuramos softwares que contivessem principalmente atividades de associação, correspondência, alfabetização e introdução à matemática.

Fizemos a busca por intermédio do descritor "Softwares Educativos", excluindo aqueles que eram usados diretamente na internet, pelo fato de nem sempre tê-la disponível nos laboratórios de informática das escolas pesquisadas. Além desses critérios, seguimos a perspectiva de Cristóvam (2007), para o qual as atividades dos softwares educativos devem ser apresentadas de maneira objetiva, priorizando a criatividade e a interatividade do usuário, fornecendo sempre feedback, além de serem estimulantes, provocativas e desafiadoras.

De acordo com os critérios pontuados, encontramos 42 softwares educativos. Nem todos eles foram testados pela pesquisadora, visto que muitos softwares não são gratuitos e não foi possível adquirir todos, mas foram visualizadas suas telas bem como as informaçóes sobre o uso em blogs e fóruns de internet cujo tema era informática na educação.

Conforme a classificação de Valente (1993), os softwares selecionados são categorizados como exercício e prática. Escolhemos três softwares educativos para cada aluno, para que também fosse observada a facilidade de sua utilização. Ressaltamos que o software educativo "GCompris 7" já era adotado em uma das escolas, de maneira que optamos por apresentar aos professores outros softwares educativos, além de auxiliá-los no manuseio dos softwares de que a escola dispunha.

${ }^{7}$ GCompris é uma suíte de aplicaçóes educacionais que compreende numerosas atividades para crianças de idade entre dois e 10 anos. Algumas das atividades são de orientação lúdica, mas sempre com um caráter educacional. Fonte: http://gcompris.net/-pt-. 
O Quadro 2 focaliza os softwares educativos selecionados inicialmente para as intervenções com os alunos.

Quadro 2- Softwares Educativos selecionados para as intervençóes.

\begin{tabular}{|l|l|}
\hline Aluno & \multicolumn{1}{|c|}{ Softwares Educativos } \\
\hline João & Coelho Sabido Maternal, 101 Exercícios. \\
\hline Marcos & 101 Exercícios, Ensino Fundamental I. \\
\hline Mário & Coelho Sabido Maternal, 101 Exercícios. \\
\hline José & Ensino Fundamental I, Ensino Fundamental II. \\
\hline Maria & Ensino Fundamental I, Ensino Fundamental II. \\
\hline Fernando & Coelho Sabido Maternal, 101 Exercícios. \\
\hline
\end{tabular}

Fonte: Elaboração Própria

Cada um dos softwares educativos selecionados reunia diversas atividades, abordando os mais variados conteúdos; assim, para cada intervenção, selecionávamos atividades de acordo com os objetivos e conteúdos que constavam no planejamento da intervenção semanal.

\subsection{Planejamentos das Intervençóes}

Os planejamentos das atividades de informática aconteciam semanalmente, visto que levávamos em consideração o desempenho do aluno na última intervenção e também os conteúdos pedagógicos que estavam sendo trabalhados naquela semana, na sala de aula.

As professoras envolvidas na pesquisa informavam semanalmente os conteúdos que estavam sendo desenvolvidos com os alunos com DI, os quais nem sempre acompanhavam tais conteúdos com o restante da turma. A partir desse conteúdo e baseando-nos nas observaçóes realizadas a respeito do desempenho dos alunos, buscávamos nos softwares selecionados algumas atividades que contemplassem o conteúdo tratado em sala de aula e as indicávamos às professoras. Após ouvir a opinião da professora e a troca de experiências com a pesquisadora, finalizávamos o planejamento. Salientamos que, além dessas ações com objetivos pedagógicos, eram igualmente propostas certas atividades destinadas a favorecer a manipulação dos componentes periféricos do computador, pois alguns alunos tinham dificuldade.

Durante as intervençóes, a pesquisadora fazia o papel de mediadora das atividades, sendo que os alunos participantes precisavam de atenção constante, enquanto a professora da sala orientava os demais alunos, na realização da atividade. Em alguns momentos, a professora se aproximava e observava como acontecia o desenvolvimento das atividades.

Nas duas escolas (A e B), os instrutores de informática não auxiliavam diretamente os alunos, mas apenas ofereciam suporte em relação à manipulação dos equipamentos, chamando a atenção dos estudantes, quando necessário.

Foram planejadas 66 intervenções, iniciadas em setembro e com término em dezembro; no entanto, em função de algumas variáveis intervenientes (feriados, pontos 
facultativos, falta de alunos etc.), foram efetivadas 55 intervençóes com duração de 40 minutos (tempo da aula de informática).

\subsection{ANÁLISE DOS DADOS}

A apresentação dos resultados ocorrerá de maneira descritiva e estes serão analisados quantitativa e qualitativamente, considerando a realidade observada, as anotaçóes de campo e as intervençóes por meio dos softwares, fundamentados nos conceitos de mediação e ZPD da teoria histórico-cultural e com o que pontua o referencial teórico do trabalho, tendo em vista o objetivo principal de investigar como estavam planejadas as atividades de informática, para alunos com DI, e propor atividades adicionais, por meio de softwares educativos.

\section{Resultados}

Anteriormente às intervençóes de pesquisa, os participantes frequentavam as aulas de informática, porém, a maioria deles tinha dificuldades em manusear os componentes periféricos (teclado e mouse), o que também dificultava a realização das atividades nos softwares educativos. Em decorrência, foi necessário sugerir atividades, para alguns estudantes, as quais possibilitassem desenvolver habilidades para manusear o mouse, sendo este o principal componente periférico empregado nas intervençóes. Salientamos que esses alunos exibiam dificuldade, não por incapacidade motora, mas por falta de experiência adequada.

Nas intervençôes com os alunos do $1^{\circ}$ ano do Ensino Fundamental I, foram propostas atividades, primeiramente com o software educativo Coelho Sabido Maternal, por não terem prática no trabalho com o computador, sendo preciso, num primeiro momento, proporcionar-lhes o acesso ao equipamento, por meio do treino do controle do mouse, durante a realização das atividades. Ressaltamos que esse software é de manuseio simples: para realizar as atividades, basta que o aluno movimente e/ou posicione o mouse, o que facilita a manipulação dos componentes periféricos, além de trabalhar com conteúdos pedagógicos de maneira simples e lúdica.

Com os alunos do $3^{\circ}$ ano e $4^{\mathrm{a}}$ série do Ensino Fundamental I, optamos por atividades que, por meio de jogos lúdicos, trabalhassem conteúdos essenciais para os anos iniciais do Ensino Fundamental, como escrita, leitura e operaçóes matemáticas. Com os participantes da $4^{\mathrm{a}}$ série, foram propostas atividades enfocando a escrita e a leitura, enfatizando também algumas regras ortográficas. Além dos conteúdos de língua portuguesa, algumas atividades trabalhavam operaçóes matemáticas e alguns conceitos importantes da área de ciências. As atividades selecionadas nos softwares se distribuíam por diferentes níveis de dificuldade: conforme os alunos faziam as atividades corretamente, eram direcionados a atividades com grau maior de dificuldade. A Figura 1 apresenta o número de intervençóes realizadas com cada aluno. 
Figura 1 - Número de intervençóes de pesquisa realizada com cada aluno.

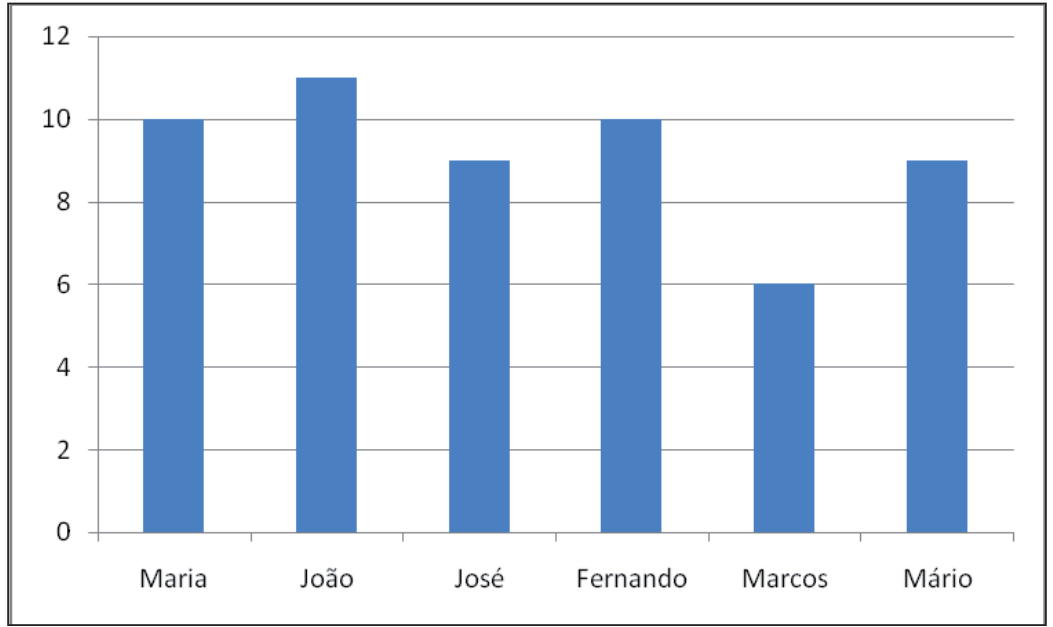

Fonte: Elaboração Própria

Além da escolha do software educativo, da seleção e planejamento das atividades, utilizamos estratégias educativas capazes de fazer a mediação da atividade e a realização por parte dos alunos.

A Figura 2 traz o número de estratégias da categoria "manipulação dos componentes periféricos do computador (acesso à máquina)”, executadas com cada um dos alunos participantes.

Figura 2 - Número de estratégias da categoria "manipulação dos componentes periféricos do computador (acesso à máquina)".

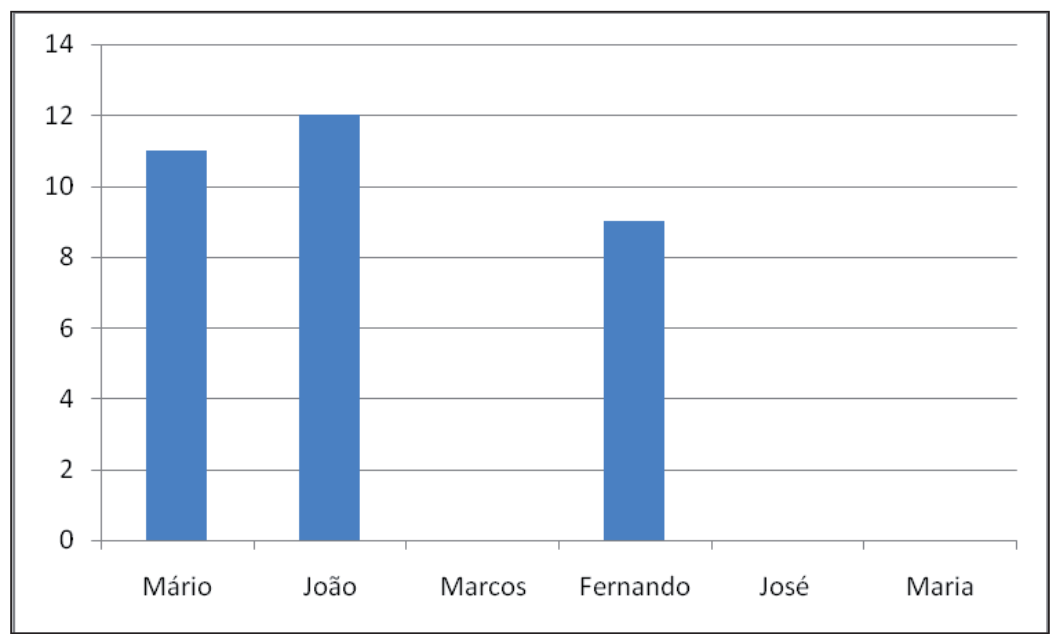

Fonte: Elaboração Própria 
A Figura 3 apresenta o número de estratégias da categoria "compreensão da atividade e do conteúdo pedagógico" utilizadas com cada um dos participantes. Essas estratégias, além de facilitar a compreensão do conteúdo e favorecer a realização das atividades, permitiram que os alunos entendessem o objetivo do jogo e o conteúdo pedagógico que estava sendo trabalhado naquele momento, de maneira que o objetivo da atividade não fosse unicamente vencer o jogo.

Figura 3 - Número de estratégias da categoria “compreensão da atividade e do conteúdo pedagógico".

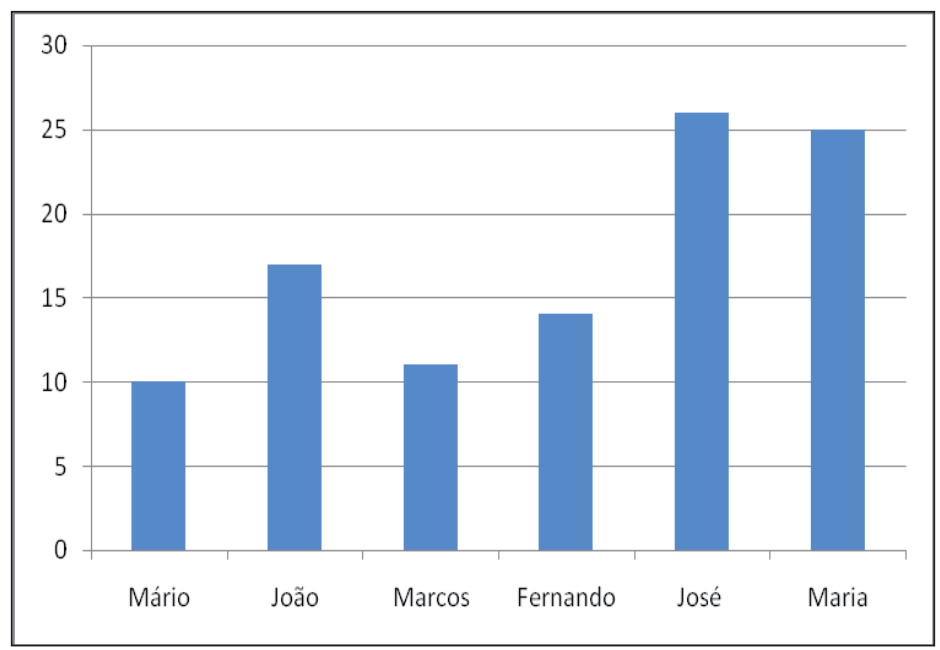

Fonte: Elaboração Própria

A Figura 4 contém o número de estratégias empregadas em cada uma das categorias definidas ao longo das intervenções.

Figura 4 - Número de estratégias utilizadas em cada categoria.

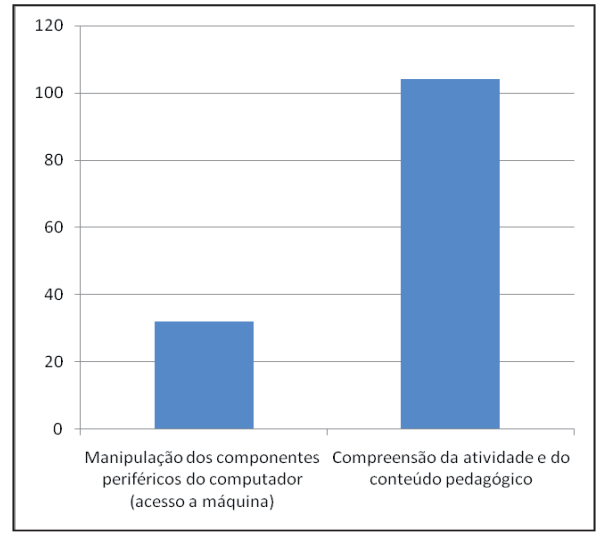

Fonte: Elaboração Própria 


\section{Discussóes}

Como se pode observar na Figura 1, o número de intervençóes por aluno variou entre seis e 11, explicando-se a diferença pelo elevado número de faltas de alguns estudantes, por feriados nacionais e ainda pelos dias que antecederam a eleiçáo presidencial de 2010, visto que essas escolas eram locais de votaçáo e, nessas ocasióes, as aulas foram suspensas. Essas diferenças no número de intervençóes podem ter afetado o aproveitamento maior daqueles que faltaram mais ou mesmo foram prejudicados pelos feriados e pontos facultativos. No entanto, nosso foco principal são as estratégias, que discutiremos a seguir.

As estratégias acionadas durante as intervençóes foram divididas em duas categorias: estratégias para manipulação dos componentes periféricos do computador (acesso à máquina) e estratégias para a compreensão da atividade e do conteúdo pedagógico.

Algumas atividades eram propostas em duas ou mais intervençóes, porque nem sempre o desempenho do aluno era satisfatório em uma única aplicação da atividade e também para possibilitar que uma atividade que o aluno realizou com auxílio pudesse ser feita por ele sozinho, após algumas tentativas. Sendo assim, algumas atividades eram sugeridas mais de uma vez, de sorte que determinadas estratégias se mantinham e outras eram pensadas para auxiliar a compreensão e a execução da atividade, por parte do aluno.

Apresentamos, na sequência, um exemplo para cada uma das categorias de estratégias:

1. Estratégia usada com o aluno José, durante o desenvolvimento da atividade "Digitando" fazer a leitura pausada da palavra, dando ênfase em cada sílaba.

2. Estratégia utilizada com o aluno Fernando, durante o desenvolvimento da atividade "Brincando nas Nuvens" - empregar o mouse junto com o aluno, controlando os movimentos para que fosse possível encaixar as peças na figura.

O exemplo 1 demonstra a categoria "manipulação dos componentes periféricos do computador (acesso à máquina)", enquanto o exemplo 2 demonstra a categoria "compreensão da atividade e do conteúdo pedagógico".

Em função do nível de desenvolvimento dos alunos, apelamos para diversas estratégias, com objetivo de simplificar e facilitar o desenvolvimento da atividade, como, por exemplo: repetir pausadamente (dando ênfase em cada sílaba) as palavras que deveriam ser escritas, nomear figuras, usar desenhos e objetos para realizar operaçóes matemáticas etc. Porém, essas estratégias poderiam ser adotadas com qualquer aluno que também apresentasse essas dificuldades.

O uso das estratégias e a mediação do professor estavam presentes em todos os momentos das intervençóes, tanto para que o aluno compreendesse o que deveria ser feito, em determinada atividade, quanto para acompanhar o desenvolvimento da mesma e propor, em alguns momentos, que o aluno executasse a atividade mais de uma vez ou que avançasse no nível de dificuldade.

Pontuamos ainda que as tecnologias devem ser utilizadas de acordo com os propósitos educacionais da escola, com estratégias adequadas para propiciar ao aluno a aprendizagem. A 
simples inserção do recurso pedagógico e/ou tecnológico não contribui para a aprendizagem (BERNARDI, 2010).

Observamos, na Figura 2, que dois alunos (entre os seis participantes) do primeiro ano (Mário e João) e o aluno Fernando, do terceiro ano, precisaram de estratégias que facilitassem o manuseio dos componentes periféricos do computador e, dessa maneira, favorecessem o acesso à máquina. Vale ressaltar que, desde o início do ano, os alunos Mário e João estavam em contato com o computador no ambiente escolar, ao passo que Fernando não tinha participação efetiva na aula de informática, por resistência do instrutor.

José e Maria, que não necessitaram de estratégias específicas para trabalhar com o computador, já demonstravam um bom domínio para a utilização dos componentes periféricos, embora as atividades inicialmente propostas pela professora fossem inadequadas aos seus níveis de desenvolvimento. $\mathrm{O}$ aluno Marcos mostrava igualmente bom domínio, mas empregava o teclado de colmeia, recurso que levava ao manuseio do teclado sem grandes dificuldades.

Masseto (1995) aponta que as estratégias permitem a motivação e a participação do aluno e atendem às diferenças individuais. As estratégias incluídas em nossa pesquisa, contemplando as duas categorias elencadas, foram imprescindíveis para que os participantes usassem o computador e/ou softwares educativos como um recurso pedagógico.

Verificamos, na categoria "compreensão da atividade e do conteúdo pedagógico" (Figura 3), variações significativas em relação ao número de estratégias usadas com cada aluno, nas diferentes atividades. Isso se deve à quantidade de atividades propostas em cada intervenção, visto que geralmente era adotada uma estratégia para cada atividade proposta, e os alunos que mais se serviram dessa categoria de estratégia efetuaram um maior número de atividades por intervenção.

Com Maria e José foi possível um número maior de estratégias, devido ao maior nível de desenvolvimento desses alunos e por já dominarem os componentes periféricos para o trabalho com o computador, características propor as quais garantiram maior número de atividades em cada intervenção, em relação aos demais.

Apesar de a maioria das atividades dos softwares educativos ser autoexplicativa, as estratégias eram imprescindíveis para que o aluno compreendesse o objetivo do jogo e o conteúdo pedagógico abordado. Um exemplo dessa situação eram os jogos de memória; para realização dessas atividades, era preciso que o aluno compreendesse qual carta deveria ser encontrada, como, por exemplo, que ele realizasse a operação matemática para depois encontrar a carta correspondente. Sem esse entendimento, o aluno abriria as cartas aleatoriamente, sem compreender o conteúdo exigido naquela atividade.

As estratégias empregadas não eram específicas para alunos com DI, mas necessárias para qualquer aluno sem muita familiaridade com o computador e seus componentes, assim como com as atividades próprias dos softwares educativos. Conforme Manzini (2010), estratégia é toda ação do professor, que geralmente utiliza um recurso pedagógico para alcançar um objetivo de ensino e deve estar presente em toda atividade a ser desenvolvida. 
Percebemos, na Figura 4, a diferença no número de estratégias de cada uma das categorias. Tal diferença se explica pelo fato de as estratégias categorizadas como "manipulação dos componentes periféricos do computador (acesso à máquina)" terem sido utilizadas apenas com João, Mário e Fernando, tendo a outra categoria de estratégias sido aplicada a todos os participantes. Além disso, as estratégias categorizadas como "manipulação dos componentes periféricos do computador" não eram necessárias em todas as atividades propostas, mas apenas quando os alunos apresentavam dificuldade, enquanto a outra categoria de estratégias era acionada em todas as intervençóes, sendo geralmente uma para cada atividade, já que eram imprescindíveis para que os alunos compreendessem o objetivo das atividades.

A utilização de grande número de estratégias categorizadas como "compreensão da atividade e do conteúdo pedagógico" aponta que as maiores dificuldades dos alunos estavam na compreensão dos conteúdos pedagógicos, e tais estratégias proporcionaram a realização das atividades corretamente.

Os estudos de Bezerra (2010) apontaram a necessidade de estratégias diferenciadas de ensino para incluir alunos com deficiência, nas aulas de educação física. Em sua investigação, foram usadas estratégias para organização dos alunos, instrução, adaptação entre outras. Em nossa pesquisa, observamos que as estratégias mais utilizadas foram também de instrução, levando os alunos a compreender a dinâmica e o conteúdo pedagógico abordado nas atividades.

Apesar da importância da escolha do software educativo e do planejamento das atividades, observamos que foram as estratégias de ensino que possibilitaram aos alunos participantes compreender e realizar corretamente as atividades propostas.

Sendo assim, o uso do computador para fins educacionais só faz sentido na medida em que os professores o conceberem como uma ferramenta de auxílio para suas atividades didático-pedagógicas, como recurso que motiva e ao mesmo tempo desafia o surgimento de novas práticas (TEIXEIRA; BRANDÃO, 2003).

Dessa maneira, o educador assume o papel de mediador, oferecendo suporte ao aluno na sua ZPD (VYGOTSKY, 1984; VIANNA, 2006; SILVA; LIMA, 2011). Nessa perspectiva, o computador e/ou softwares educativos são concebidos como recurso pedagógico que necessitam de uma mediação do professor, a fim de que possam ser efetivos para o processo de ensinoaprendizagem dos alunos.

\section{Conclusốes}

Verificamos que alguns dos alunos participantes tinham dificuldade para manusear os componentes periféricos do computador, como mouse e teclado. Consideramos que a dificuldade dos alunos em manipulá-los não se dava por incapacidade, mas sim por falta de experiência adequada.

A utilização de softwares educativos, durante as intervençôes, demonstrou que se os conteúdos trabalhados nas aulas de informática convergirem com as atividades propostas em sala de aula, os alunos com DI têm maiores oportunidades de experienciar atividades diferenciadas que lhes possibilitam o sucesso. Além disso, a escolha do software 
educativo e o planejamento das atividades são importantes, mas precisam associar-se à adoção de estratégias mediadas pelo professor. Observamos que foram as estratégias de ensino que permitiram aos participantes a compreensão e a realização correta das atividades propostas, lembrando que o uso de estratégias é imprescindível para qualquer recurso pedagógico, seja ele proposto a um aluno com ou sem deficiência.

Ao longo da pesquisa, fomos percebendo que apenas os conhecimentos técnicos a respeito dos softwares educativos e os pedagógicos sobre o conteúdo trabalhado não são suficientes para que a atividade proposta contribua para o desenvolvimento de alunos com DI; é preciso que o professor atente para as habilidades e dificuldades desses alunos e recorra a estratégias que possibilitem o entendimento da atividade, a compreensão do conteúdo, paralelamente à necessidade da atuação conjunta entre os profissionais da área de informática e os professores da escola, para selecionar os softwares mais adequados ao desenvolvimento e características dos alunos.

\section{REFERÊNCIAS}

BERNARDI, S. T. Utilização de softwares educativos nos processos de alfabetização de ensino e aprendizagem com uma visão psicopedagógica. Revista de Educação do IDEAU (Instituto de Desenvolvimento do Alto Uruguai), Getulio Vargas, v.5, n.10, p.1-15, 2010.

BEZERRA, A. F. S. Estratégias para o ensino inclusivo de alunos com deficiência nas aulas de Educação Física. 2010. 108p. Tese (Doutorado em Educação) - Faculdade de Filosofia e Ciência de Marília, Universidade Estadual Paulista, Marília, 2010

BORGES NETO, H. Uma classificação sobre a utilização do computador pela escola. Revista Educação em Debate, Fortaleza, v. 1, n. 27, p. 135-138, 1999.

CRISTÓVAM, E. H. Desenvolvimento De Um Software De Autoria Para Alunos Deficientes Não-Falantes Nas Atividades De Contos E Recontos De Histórias. 2007. 110f. Dissertação (Mestrado em Educação) Faculdade de Filosofia e Ciência de Marília,Universidade Estadual Paulista, Marília, 2007.

DANNA, M. F.; MATOS, M. F. Ensinando observação: uma introdução. 4. ed. São Paulo: Edicon, 1999.

DELVILLE, J. et al. Promoção da saúde na educação especializada. In: LEPOT-FROMENT, C. (Org.). Educação Especializada: pesquisa e indicaçóes para a ação. Bauru: EDUSC, 1999. p. 193-209.

GARCIA, R. M. C. O conceito de flexibilidade curricular nas políticas públicas de inclusão educacional. In: JESUS, D. M.; BARRETO, M. A. S. C.; VICTOR, S. L. (Org.). Inclusão: práticas pedagógicas e trajetórias de pesquisa. Porto Alegre: Mediação, 2007. p.11-20.

LIMA, C. R. U. Acessibilidade tecnológica e pedagógica na apropriação das tecnologias de informação e comunicação por pessoas com necessidades educacionais especiais. 2003, 186 f. Dissertação (Mestrado em Educação) - Faculdade de Educação, Universidade Federal do Rio Grande do Sul, Porto Alegre, 2003.

MANZINI, E. J. Recurso pedagógico adaptado e estratégias para o ensino de alunos com deficiência física. In: MANZINI, E. J. ; FUJISAWA, D. S. (Org.). Jogos e recursos para comunicação e ensino na educação especial. Marília: ABPEE, 2010. p. 111-132.

MASSETTO, M. Didática: a aula como centro. São Paulo: FTB, 1995. 
MIRANDA, T. G. Aplicação das Tecnologia Assistiva, de Informação e Comunicação em Educação Especial. In: MENDES, E. G.; ALMEIDA, M. A.; HAYASHI, M. C. P. I. (Org.). Temas em Educação Especial: conhecimentos para fundamentar a prática. Araraquara: Junqueira\&Marin, 2008. p. 134-144. OLIVEIRA, M. K. Vygotsky: Aprendizado e desenvolvimento sócio-histórico. São Paulo: Scipione, 1993.

OLIVEIRA, R. Informática educativa: dos planos e discursos à sala de aula. Campinas, SP: Papirus, 1997.

SCHMITZ, E. Recursos Tecnológicos na Formação do Professor. Revista Educação UNISINOS, São Leopoldo, v 6, n. 10, p. 37-73, 2002

SILVA, A. M.; LIMA, C. M. Práticas docentes no uso do computador no processo educativo: abordagens de ensino e aprendizagem. In: ENCONTRO DE PESQUISA EM EDUCAÇÃO DA REGIÃO SUDESTE - ANPED SUDESTE, 2011, Rio de Janeiro. Anais eletrônicos... Rio de Janeiro: Universidade Federal do Rio de Janeiro, 2010. Disponível em: <http:/www.fe.ufrj.br/anpedinha2011/ anais/anais.php>. Acesso em: 29 jul. 2011.

SILVA, C. M. O. Criança-professor-computador: possibilidades interativas e sociais na sala de aula. Revista de Humanidades, Fortaleza, v. 21 n. 2, p.151-136, 2006.

TEIXEIRA, A. C.; BRANDĀO, E. J. R. Software Educativo: o difícil começo. Revista Novas Tecnologias na Educação. Rio Grande do Sul, v.1, n.1, p.1-17, 2003.

VALENTE, J.A. Diferentes usos do computador na educação. In: VALENTE, J. A. (Org.). Computadores e conhecimento: repensando a educação. Campinas: Gráfica Central da Unicamp, 1993. p. 5-23.

VIANNA, P. B. M. Formação de professores/mediadores para o uso das TIC: elementos teóricos e práticos trabalhados em uma pesquisa-ação. UNIRevista, São Leopoldo, v.1, n.2, abril, p.1-12, 2006 VYGOTSKY, L. S. A formação social da mente: o desenvolvimento dos processos psicológicos superiores. São Paulo: Martins Fontes, 1984.

Recebido em: 03/05/2012

Reformulado em: 17/12/2012

Aprovado em: 30/03/2013 